\title{
Comparison of transvaginal sonography and saline infusion sonohysterography for the diagnosis of causes of abnormal uterine bleeding: a diagnostic accuracy study
}

\author{
Alok S. Goyal ${ }^{1}$, Sejal jaydip chaudhari ${ }^{1}$, Anjani R. Shrivastava ${ }^{2}$, Ragini N. Verma $^{2}$
}

${ }^{1}$ Department of Obstetrics and Gynaecology, GMERS Medical College Valsad, Gujarat, India
${ }^{2}$ Department of Obstetrics and Gynaecology, GMC Medical College Surat, Gujarat, India

Received: 10 March 2016

Accepted: 07 April 2016

*Correspondence:

Dr. Alok S. Goyal,

E-mail: alokgoyaldr@gmail.com

Copyright: ( ) the author(s), publisher and licensee Medip Academy. This is an open-access article distributed under the terms of the Creative Commons Attribution Non-Commercial License, which permits unrestricted non-commercial use, distribution, and reproduction in any medium, provided the original work is properly cited.

\section{ABSTRACT}

Background: Abnormal uterine bleeding (AUB) is one of the frequently observed gynecological problems in outpatient settings. Diagnosis of the cause of AUB is important and hysteroscopy with biopsy is considered is best method for diagnosis of the same. Recent studies suggest the role of transvaginal sonography (TVS) and saline infusion sonohysterography (SIS) for the diagnosis of AUB though data about accuracy and comparison of these techniques with gold standard is not available. The study was designed with the aim of comparison of TVS and SIS for the diagnosis of abnormal uterine bleeding in reference to microscopical examination after hysterectomy.

Methods: 100 consecutive patients of AUB were included in the study on the basis of inclusion and exclusion criteria. TVS and SIS were performed on each patient before the surgery for hysterectomy. The findings of TVS and SIS were compared with microscopical examination of the specimen after the hysterectomy. Sensitivity, specificity, positive predictive and negative predictive values were measured.

Results: For sub mucosal myoma sensitivity, specificity, positive predictive value, negative predictive value and kappa statistics of SIS were 100\%, 100\%, 100\%, 100\%, 1 respectively while for TVS It were $18.1 \%, 98.8 \%, 66.6 \%$, $90.7 \%$ and 0.25 respectively.

Conclusions: SIS has superior diagnostic accuracy and compared to TVS. These findings need to be confirmed by randomized studies with more sample size.

Keywords: AUB, SIS, TVS, Hysterectomy

\section{INTRODUCTION}

Abnormal uterine bleeding (AUB) is one of the common gynaecologic complaints observed at outpatient department. The AUB may be because of the various reasons which may vary from simple dysfunction uterine bleeding to endometrial cancer. Thorough investigations need to rule out organic causes specifically in postmenopausal and perimenopausal age women, as chances of endometrial carcinoma in such women is high. ${ }^{1}$
Hysteroscopy with directed biopsy is considered as a standard investigation for AUB because of its precision. However it is not used as primary diagnostic procedure because of its high cost and invasive nature. ${ }^{2}$ Transvaginal sonography (TVS) is also considered as useful method for evaluation of AUB, but it has some limitations for screening the lesions within the endometrial cavity. Thickened endometrium seen on TVS may be because of many reasons like polyp, fibroids, carcinoma or endometrial hyperplasia hence findings are not specific. Also, because of limitations of double layer thickness evaluation many focal lesions remain 
undiagnosed in TVS. ${ }^{3}$ Another such technique is saline infusion sonohysterography (SIS) in which the single layer evaluation of the endometrial lining is done by injecting saline during ultrasonic examination and it can be useful in differentiating single and distinguish focal from diffuse endometrial conditions. Few studies published so far indicated that SIS may have some advantages as compared to the TVS in differentiating diffuse mass but there is no clear advantage observed and more exploration is needed in this area. ${ }^{4-6}$

The study was designed with the aim of comparison of SIS and TVS for detecting intracavitary abnormalities in women with abnormal uterine bleeding, using the final diagnosis, established at hysterectomy as reference.

\section{METHODS}

This study was done at department of obstetrics and gynecology of tertiary care centre of Gujarat, India from September 2011 to October 2013 after obtaining permission from the institutional ethics committee. In this prospective study, 100 consecutive premenopausal patients with abnormal uterine bleeding were included in the study. Only those women having AUB with uterine size less than 12 weeks and having no other significant medical history were included in the study. Patients having acute pelvic infection, pregnancy, endometrial carcinoma (diagnosed/suspected) were excluded from the analysis.

Procedure of this study detailed history was taken and relevant examination was done. TVS and SIS were performed with the help of $5.0 \mathrm{MHz}$ vaginal probe a day before surgery. After performing baseline ultrasound the uterus was imaged in the sagittal plane, which includes the entire length of cervical canal. As per the TVS normal endometrium and uterine cavity were defined by a centrally placed echo-dense line within the uterus and a homogeneous endometrial lining with distinct margins to the myometrium. Thickness of endometrium was measured from basalis to basalis in the longitudinal plane. Both wall of the endometrium individually and added together was used for measuring endometrial thickness on SIS. SIS was performed just after TVS without scheduling for the phase of the menstrual cycle. F or SIS 8 numbers or 10 numbers. Foley's catheter was introduced into uterine cavity, bulb inflated with $3 \mathrm{ml}$ of normal saline and mild traction given so as to place the bulb at the internal os. $50 \mathrm{ml}$ of syringe contain normal saline was attached to the catheter. Vaginal probe was introduced and sterile saline was infused until the distension of uterine cavity was adequate to see any lesion or till pain appears and findings were noted. 15 to $30 \mathrm{ml}$ saline was used in the majority cases.

Macroscopic inspection of hysterectomy specimen and histological examination were compared with the findings at SIS and TVS. Investigators involved in examination of these specimens were not aware about the findings of each other.

\section{Statistics}

Descriptive statistics was reported in the form of frequency, percentages, mean and standard deviation based on type of data. Sensitivity, specificity, positive predictive value, negative predictive values were calculated. Cohen's kappa was used to see agreement between the procedures, value of Cohen's kappa $>0.75$ was considered excellent agreement, value between 0.40 to 0.75 was considered as intermediate to good agreement and value less than 0.40 was considered as poor agreement. Open epi software and SPSS Version 17 was used for data analysis.

\section{RESULTS}

Majority of patient (92\%) were between ages 31-50 years. More than $50 \%$ of patients were having uterine size between bulky to 6 week. Menorrhagia and polymenorrhea was most common complain on presentation. As per the histopathology report, among the patients with abnormal histopathology, most common types were Intramural myoma (19\%) and adenomyosis (17\%) (Table 1).

Table 1: Demographical and clinical parameters of the subjects included in the study.

\begin{tabular}{|ll|}
\hline Parameters & Sulbjects (n=100) \\
\hline Age (years) & $48(48)$ \\
\hline $31-40$ & $44(44)$ \\
\hline $41-50$ & $08(8)$ \\
\hline $51-60$ & $13(13)$ \\
\hline Uterine size & $51(51)$ \\
\hline Normal & $21(21)$ \\
\hline Bulky to 6 weeks & $09(9)$ \\
\hline $6-8$ weeks & $06(6)$ \\
\hline $8-10$ weeks & \\
\hline $10-12$ weeks & $46(46)$ \\
\hline Symptoms & $19(19)$ \\
\hline Menorrhagia & $14(14)$ \\
\hline Polymenorrhea & $06(6)$ \\
\hline Dysmenorrhea & $07(7)$ \\
\hline Metrorrhagia & $08(8)$ \\
\hline Menometrorragia & \\
\hline Continuous bleeding per vaginal & $19(19)$ \\
\hline HPE report & $11(11)$ \\
\hline Intramural myoma & $07(7)$ \\
\hline Submucosal myoma & $17(17)$ \\
\hline Polyp & $12(12)$ \\
\hline Adenomyosis & $34(34)$ \\
\hline Abnormal endometrium & \\
\hline Normal endometrium & \\
\hline Values in parentesis are percentages & \\
\hline
\end{tabular}

Values in parenthesis are percentages. 
Comparison of TVS and SIS findings with histopathology examination is mentioned in table 2. TVS findings were not correlated well with sub mucosal myoma and polyp and abnormal endometrium whereas SIS findings correlated well with intra operative findings and HPE.

(Table 3) shows comparison of TVS findings with HPE reports. It shows that, 9 cases of sub mucosal myoma were falsely diagnosed as intramural myoma (2), polyp (1), adenomyosis (2), abnormal endometrium (3), and normal (1) on TVS. Out of 7 cases polyp, 5 cases were falsely diagnosed as abnormal endometrium on TVS. 3 cases of abnormal endometrium were falsely diagnosed as sub mucosal myoma (1) and polyp (2) on TVS. For TVS findings for sub mucosal myoma false positive was 1, false negative were 9 , sensitivity $18.18 \%$ and specificity $98.88 \%$. For polyp false positive were 3 , false negative were 5 , sensitivity $28.57 \%$ and specificity $96.77 \%$.

Table 2: Comparison of TVS and SIS findings with intra operative hysterectomy and HPE.

\begin{tabular}{|llll|}
\hline & TVS & SIS & HPE \\
\hline Intramural myoma & $18(18)$ & $19(19)$ & $19(19)$ \\
\hline Sub mucosal myoma & $03(3)$ & $11(11)$ & $11(11)$ \\
\hline Polyp & $05(5)$ & $09(9)$ & $07(7)$ \\
\hline Adenomyosis & $19(19)$ & $18(18)$ & $17(17)$ \\
\hline $\begin{array}{l}\text { Abnormal } \\
\text { endometrium }\end{array}$ & $19(19)$ & $12(12)$ & $12(12)$ \\
\hline Normal endometrium & $36(36)$ & $31(31)$ & $34(34)$ \\
\hline
\end{tabular}

Values in parenthesis are percentages.

Table 3: Comparison of TVS findings with HPE report.

\begin{tabular}{|c|c|c|c|c|c|c|c|}
\hline HPE/TVS & $\begin{array}{l}\text { Intramural } \\
\text { myoma } \\
(n=19)\end{array}$ & $\begin{array}{l}\text { Sub mucosal } \\
\text { myoma } \\
(\mathrm{n}=11)\end{array}$ & $\begin{array}{l}\text { Polyp } \\
(\mathrm{n}=7)\end{array}$ & $\begin{array}{l}\text { Adenomyosis } \\
(\mathrm{n}=17)\end{array}$ & $\begin{array}{l}\text { Abnormal } \\
\text { endometrium } \\
(\mathrm{n}=12)\end{array}$ & $\begin{array}{l}\text { Normal } \\
(n=34)\end{array}$ & $\begin{array}{l}\text { Total } \\
(n=100)\end{array}$ \\
\hline $\begin{array}{l}\text { Intramural } \\
\text { myoma }\end{array}$ & 16 & 2 & 0 & 0 & 0 & 0 & 18 \\
\hline $\begin{array}{l}\text { Sub mucosal } \\
\text { myoma }\end{array}$ & 0 & 2 & 0 & 0 & 1 & 0 & 3 \\
\hline Polyp & 0 & 1 & 2 & 0 & 2 & 0 & 5 \\
\hline Adenomyosis & 1 & 2 & 0 & 14 & 0 & 2 & 19 \\
\hline $\begin{array}{l}\text { Abnormal } \\
\text { endometrium }\end{array}$ & 0 & 3 & 5 & 0 & 9 & 2 & 19 \\
\hline Normal & 2 & 1 & 0 & 3 & 0 & 30 & 36 \\
\hline
\end{tabular}

Table 4: Comparison of SIS findings with HPE report.

\begin{tabular}{|c|c|c|c|c|c|c|c|}
\hline HPE/SIS & $\begin{array}{l}\text { Intramura } \\
\text { l myoma } \\
(n=19)\end{array}$ & $\begin{array}{l}\text { Sub mucosal } \\
\text { myoma } \\
(\mathrm{n}=11)\end{array}$ & $\begin{array}{l}\text { Polyp } \\
(\mathrm{n}=7)\end{array}$ & $\begin{array}{l}\text { Adenomyosis } \\
(\mathbf{n}=17)\end{array}$ & $\begin{array}{l}\text { Abnormal } \\
\text { endometrium } \\
(\mathrm{n}=12)\end{array}$ & $\begin{array}{l}\text { Normal } \\
(n=34)\end{array}$ & $\begin{array}{l}\text { Total } \\
(n=100)\end{array}$ \\
\hline Intramural myoma & 19 & 0 & 0 & 0 & 0 & 0 & 19 \\
\hline Sub mucosal myoma & 0 & 11 & 0 & 0 & 0 & 0 & 11 \\
\hline Polyp & 0 & 0 & 7 & 0 & 2 & 0 & 9 \\
\hline Adenomyosis & 0 & 0 & 0 & 16 & 0 & 2 & 18 \\
\hline Abnormal endometrium & 0 & 0 & 0 & 0 & 10 & 2 & 12 \\
\hline Normal & 0 & 0 & 0 & 1 & 0 & 30 & 31 \\
\hline
\end{tabular}

(Table 4) shows comparison of SIS findings with HPE reports. For intramural myoma and sub mucosal myoma SIS findings were correlated well with intra operative findings and HPE reports. In this study SIS correlation with intra operative findings and HPE for sub mucosal myoma showed sensitivity of $100 \%$ and specificity of $100 \%$ and for polyp showed sensitivity of $100 \%$ and specificity of $97.85 \%$.
Table 5 and 6 shows diagnostic performance of TVS and SIS in identifying various causes. SIS has higher sensitivity and specificity when compared with TVS.

Table 6 shows diagnostic performance of TVS and SIS. The SIS was more sensitive and specific as compared to TVS alone. The positive predictive value of SIS was $96.08 \%$ as compared to $95.56 \%$ for TVS. The diagnostic accuracy of SIS $(98 \%)$ was better than that of TVS $(92 \%)$. 
Table 5: Diagnostic performance of TVS and SIS in identifying various causes.

\begin{tabular}{|lllllll|}
\hline Test performance/diagnosis & \multicolumn{2}{c}{ Sub mucosal myoma } & Polyp & \multicolumn{2}{c|}{ Abnormal endometrium } \\
\hline Sensitivity & TVS & SIS & TVS & SIS & TVS & SIS \\
\hline Specificity & $18.18 \%$ & $100 \%$ & $28.57 \%$ & $100 \%$ & $75 \%$ & $83.33 \%$ \\
\hline PPV & $98.88 \%$ & $100 \%$ & $96.77 \%$ & $97.85 \%$ & $88.64 \%$ & $97.73 \%$ \\
\hline NPV & $66.67 \%$ & $100 \%$ & $40 \%$ & $77.78 \%$ & $47.37 \%$ & $83.33 \%$ \\
\hline DA & $90.72 \%$ & $100 \%$ & $94.74 \%$ & $100 \%$ & $96.30 \%$ & $97.73 \%$ \\
\hline Cohen's kappa & $90 \%$ & $100 \%$ & $92 \%$ & $98 \%$ & $87 \%$ & $96 \%$ \\
\hline
\end{tabular}

Table 6: Diagnostic performance of TVS and SIS.

\begin{tabular}{|c|c|c|c|c|c|c|c|}
\hline \multirow{2}{*}{ Test } & \multirow{2}{*}{ Sensitivity } & \multirow{2}{*}{ Specificity } & \multirow{2}{*}{ PPV } & \multirow{2}{*}{ NPV } & \multirow{2}{*}{ DA } & \multicolumn{2}{|c|}{ Likelihood ratio } \\
\hline & & & & & & Positive & Negative \\
\hline TVS & $\begin{array}{l}87.76 \\
(75.76-94.27)\end{array}$ & $\begin{array}{l}96.08 \\
(86.78-98.92)\end{array}$ & $\begin{array}{l}95.56 \\
(8.17-98.77)\end{array}$ & $\begin{array}{l}89.09 \\
(78.17-94.9)\end{array}$ & $\begin{array}{l}92 \\
(85-95.89)\end{array}$ & $\begin{array}{l}22.38 \\
(8.34-60)\end{array}$ & $\begin{array}{l}0.12 \\
(0.09-0.17)\end{array}$ \\
\hline SIS & $\begin{array}{l}100 \\
(92.73-100)\end{array}$ & $\begin{array}{l}96.08 \\
(86.78-98.92)\end{array}$ & $\begin{array}{l}96.08 \\
(86.78-98.92)\end{array}$ & $\begin{array}{l}100 \\
(92.73-100)\end{array}$ & $\begin{array}{l}98 \\
(93-99.45)\end{array}$ & $\begin{array}{l}25.05 \\
(9.57-67.94)\end{array}$ & 0 \\
\hline
\end{tabular}

Note Sensitivity, specificity, positive predictive value (PPV), negative predictive value (NPV), and diagnostic accuracy (DA) data are percentages. All numbers in parentheses are 95\% CIs.

\section{DISCUSSION}

This study was designed with the aim of comparison of SIS and TVS for detecting intracavitary abnormalities in women with abnormal uterine bleeding in reference to hysterectomy diagnosis.

In present study, the mean age for women was 45 years, range 32-57 years. Menorrhagia was the commonest symptom in $46 \%$ of the cases and the most common lesion was intramural myoma in $19 \%$ of the cases. TVS cannot distinguish endometrial hyperplasia from polyp as both can cause thickening of the endometrium whereas SIS can detect focal lesions from diffuse thickening. SIS has higher sensitivity and specificity when compared to TVS. Similar findings were seen in the studies by Ryu et al and Reddi PR. ${ }^{7,8}$

The sensitivity and specificity of TVS for sub mucosal myoma were $18.18 \%$ and $98.88 \%$, respectively as compared to sensitivity and specificity of SIS which were $100 \%$ and $100 \%$ respectively. The sensitivity and specificity of TVS for polyp were $28.57 \%$ and $96.77 \%$, respectively as compared to sensitivity and specificity of SIS which were $100 \%$ and $97.85 \%$ respectively. All imaging techniques have a number of false results even in experienced hands. In present study false positive and negative results were higher in TVS than SIS. 2 cases of thickened endometrium were falsely diagnosed as polyp on SIS because of blood clot in endometrial cavity. Bleeding is not a contraindication to SIS. SIS is best performed as soon as possible after the cessation of menses to avoid the misinterpretation of menstrual blood clots as intrauterine pathology.
In this study, 6 women experienced severe pain. Whereas in the study by Cicinelli et al $11 \%$ of the cases experienced severe pain. The pain due to distension of uterine cavity can be minimized if saline installation is controlled and stopped as soon as the lesion is detected. NSAID given 30 minutes prior to the procedure will typically minimize any potential discomfort.

There was no evidence of infection in our study. ${ }^{8}$

Reddi PR reported for diagnosing sub mucosal myoma TVS sensitivity was $27.3 \%$ and specificity was $85 \%$. For polyp TVS sensitivity was $71.4 \%$ and specificity was $97 \%$. 2 cases of abnormal endometrium were falsely diagnosed as polyp on SIS. ${ }^{7}$ In these 2 cases intra operatively cut section of specimen shows blood clots in endometrial cavity, which were falsely diagnosed as polyp on SIS. SIS is best performed as soon as possible after the cessation of menses, during the proliferative phase of the menstrual cycle to avoid the misinterpretation of menstrual blood clots as intrauterine pathology. Bleeding is not a contraindication to SIS. It has been observed that SIS has more accurate diagnostic parameters as compared to the TVS.

This study has some limitations. Looking at the pilot nature of this study formal sample size calculation was not done and all subjects were selected consecutively not randomly. A larger randomized comparative study with formal sample size calculation can give more accurate observations. Looking at the observed diagnostic parameters it can be concluded that SIS is superior as compared to the TVS. 


\section{CONCLUSIONS}

SIS has superior diagnostic accuracy and compared to TVS. These findings need to be confirmed by randomized studies with more sample size.

\section{Funding: No funding sources}

Conflict of interest: None declared

Ethical approval: The study was approved by the Institutional Ethics Committee

\section{REFERENCES}

1. Brenner PF. Differential diagnosis of abnormal uterine bleeding. American journal of obstetrics and gynecology. 1996;175(3Pt2):766-9.

2. Bradley LD. Diagnosis of abnormal uterine bleeding with biopsy or hysteroscopy. Menopause New York, NY. 2011;18(4):425-33.

3. Fong K, Causer P, Atri M, Lytwyn A, Kung R. Transvaginal US and hysterosonography in postmenopausal women with breast cancer receiving tamoxifen: correlation with hysteroscopy and pathologic study. Radiographics: a review publication of the Radiological Society of North America, Inc. 2003;23(1):137-50.

4. Dueholm M, Forman A, Jensen ML, Laursen H, Kracht P. Transvaginal sonography combined with saline contrast sonohysterography in evaluating the uterine cavity in premenopausal patients with abnormal uterine bleeding. Ultrasound in obstetrics and gynecology: the official journal of the International Society of Ultrasound in Obstetrics and Gynecology. 2001;18(1):54-61.

5. Epstein E, Ramirez A, Skoog L, Valentin L. Transvaginal sonography, saline contrast sonohysterography and hysteroscopy for the investigation of women with postmenopausal bleeding and endometrium $>5 \mathrm{~mm}$. Ultrasound in obstetrics and gynecology: the official journal of the International Society of Ultrasound in Obstetrics and Gynecology. 2001;18(2):157-62.

6. Ryu JA, Kim B, Lee J, Kim S, Lee SH. Comparison of transvaginal ultrasonography with hysterosonography as a screening method in patients with abnormal uterine bleeding. Korean journal of radiology: official journal of the Korean Radiological Society. 2004;5(1):39-46.

7. Reddi PR, Lakshmikanttha G. Transvaginal Sonography (TVS) and Saline Infusion Sonohysterography (SIS) in the evaluation of Abnormal Uterine Bleeding (AUB). The journal of obstetrics and gynecology of India. 2010;60:6.

8. Cicinelli E, Romano F, Anastasio PS, Blasi N, Parisi C, Galantino P. Transabdominal sonohysterography, transvaginal sonography and hysteroscopy in the evaluation of submucous myomas. Obstet Gynecol. 1995:85:42-7.

Cite this article as: Goyal AS, chaudhari SJ, Shrivastava AR, Verma RN. Comparison of transvaginal sonography and saline infusion sonohysterography for the diagnosis of causes of abnormal uterine bleeding: a diagnostic accuracy study. Int J Reprod Contracept Obstet Gynecol 2016;5:1566-70. 